\title{
Novel Conjugative Transferable Multiple Drug Resistance Plasmid pAQU1 from Photobacterium damselae subsp. damselae Isolated from Marine Aquaculture Environment
}

\author{
Lisa Nonaka $^{1 *}$, Fumito Maruyama ${ }^{2}$, Manabu Miyamoto ${ }^{1}$, Masatoshi Miyakoshi $^{3}$, Ken Kurokawa ${ }^{4}$, and \\ MICHIAKI MASUDA ${ }^{1}$

\begin{abstract}
${ }^{1}$ Department of Microbiology, Dokkyo Medical University School of Medicine, Mibu, Tochigi, 321-0293; ${ }^{2}$ Section of Bacterial Pathogenesis, Section of Microbial Genomics and Ecology, Tokyo Medical and Dental University, Graduate School of Medical and Dental Science, Bunkyo-ku, Tokyo, 113-8510; ${ }^{3}$ Department of Environmental Life Sciences, Graduate School of Life Sciences, Tohoku University, Katahira 2-1-1, Sendai 980-8577; and ${ }^{4}$ Department of Biological Information, Tokyo Institute of Technology, Graduate School of Bioscience and Biotechnology, Yokohama, Kanagawa 226-8501, Japan
\end{abstract}

(Received November 14, 2011-Accepted January 30, 2012—Published online March 23, 2012)

The emergence of drug-resistant bacteria is a severe problem in aquaculture. The ability of drug resistance genes to transfer from a bacterial cell to another is thought to be responsible for the wide dissemination of these genes in the aquaculture environment; however, little is known about the gene transfer mechanisms in marine bacteria. In this study, we show that a tetracycline-resistant strain of Photobacterium damselae subsp. damselae, isolated from seawater at a coastal aquaculture site in Japan, harbors a novel multiple drug resistance plasmid. This plasmid named pAQU1 can be transferred to Escherichia coli by conjugation. Nucleotide sequencing showed that the plasmid was 204,052 base pairs and contained 235 predicted coding sequences. Annotation showed that pAQU1 did not have known repA, suggesting a new replicon, and contained seven drug resistance genes: bla $a_{\mathrm{CARB}-9}$-like, floR, $m p h(\mathrm{~A})$-like, $m e f(\mathrm{~A})$-like, sul2, tet(M) and tet(B). The plasmid has a complete set of genes encoding the apparatus for the type IV secretion system with a unique duplication of traA. Phylogenetic analysis of the deduced amino acid sequence of relaxase encoded by traI in pAQU1 demonstrated that the conjugative transfer system of the plasmid belongs to $\mathrm{MOB}_{\mathrm{H} 12}$, a sub-group of the $\mathrm{MOB}_{\mathrm{H}}$ plasmid family, closely related to the IncA/C type of plasmids and SXT/R391 widely distributed among species of Enterobacteriaceae and Vibrionaceae. Our data suggest that conjugative transfer is involved in horizontal gene transfer among marine bacteria and provide useful insights into the molecular basis for the dissemination of drug resistance genes among bacteria in the aquaculture environment.

Key words: multi-drug resistance, conjugative plasmid, aquaculture environment

The emergence and spread of drug-resistant bacteria is a global public health problem. This problem is impacted by both human and non-human use of antimicrobial agents. For example, in aquaculture, antimicrobial agents are used prophylactically to protect cultured animals from infectious diseases and avoid economic losses. Use of antimicrobial agents leads to selection for drug-resistant bacteria (6).

The occurrence of tetracycline-resistant bacteria in the sediment and seawater of an aquaculture site significantly increased after using oxytetracycline (38). Additionally, prior acquisition of drug resistance gene(s) by bacteria is a major factor for the generation and propagation of drug-resistant bacteria. Previously, the common tetracycline resistance gene, $\operatorname{tet}(\mathrm{M})$, was found in several distantly related species of bacteria isolated from fish at an aquaculture site (23), as well as from the sediment and seawater at the same site (38); therefore, gene transfer among different species of bacteria appears to be involved in the acquisition of drug resistance gene(s) in the aquaculture setting. Previously, we found that the majority of the tet( $\mathrm{M})$-positive isolates belonged to closely

\footnotetext{
* Corresponding author. E-mail: nonaka@dokkyomed.ac.jp; Tel: +81-282-87-2131; Fax: +81-282-86-5616.
}

related genera, Vibrio and Photobacterium, suggesting that bacteria from this group might serve as an important reservoir for $\operatorname{tet}(\mathrm{M})$ in the aquaculture environment (38), and $\operatorname{tet}(\mathrm{M})$ in some bacteria could be transferred to Escherichia coli and confer drug resistance (36). Among the bacteria from this group, $P$. damselae subsp. damselae is an indigenous marine bacterium $(1,46)$ known to be pathogenic in both fish and humans. In fish, it causes septicemia in a broad range of species, e.g., damselfish and rainbow trout $(29,40,41)$. In humans, exposure to seawater or fish contaminated with $P$. damselae may cause fatal necrotizing fasciitis $(2,12,17,34$, $52,59)$. Some clinical isolates of $P$. damselae subsp. damselae are drug-resistant, leading to obstacles for chemotherapy (59); therefore, drug resistance in aquatic bacteria may possibly pose a risk for human health either directly or indirectly. To evaluate this risk, determining the characteristics of drug resistance genes carried by $P$. damselae subsp. damselae and the transfer mechanism of these genes to human enteric bacteria is required.

Here we determined the molecular basis for tetracycline resistance in a strain of Photobacterium damselae subsp. damselae isolated from seawater at a coastal aquaculture site in Japan. The results show that the strain has a transferable 
plasmid named pAQU1, of approximately 200 kilo base pairs (kbp). Nucleotide sequencing showed that the plasmid contains seven drug resistance genes and a complete set of genes encoding the apparatus for the type IV secretion system (T4SS) with a unique duplication of traA.

From the deduced amino acid sequence of the relaxase encoded by traI, pAQU1 was classified as a novel member of the $\mathrm{MOB}_{\mathrm{H}}$ plasmid family in sub-group $\mathrm{MOB}_{\mathrm{H} 12}$. The phylogenetic relationship of this plasmid compared to other known groups of plasmids and integrative conjugative elements widely distributed among the species of Enterobacteriaceae and Vibrionaceae is discussed. Many reports have shown the prevalence of drug resistance among fish pathogens (6, $24,33)$ and aquaculture environmental bacteria $(15,38)$, whereas there is little information concerning the mechanism of their emergence. Our data provide useful insights into the molecular basis for the dissemination of drug resistance genes among bacteria in the aquaculture environment and their clinical impact.

\section{Materials and Methods}

\section{Bacterial strains}

P. damselae subsp. damselae strain 04 Ya311 was isolated from seawater at a coastal aquaculture site in Japan and was used as the conjugation donor (38). Its identification was confirmed using a full-length 16S rRNA gene sequence and PCR detection of the ure C gene (39). E. coli K-12 strain W3110 (whole genome sequence accession no. AP000091; 19) was obtained from the National BioResource Project (National Institute of Genetics, Japan) and used as the conjugation recipient. Rifampicin-resistant W3110Rif ${ }^{\mathrm{r}}$, used as the recipient in the alternative transfer experiment, was artificially obtained by induction. The $P$. damselae subsp. damselae donor strain was cultured in brain heart infusion medium (BHI; BD, Franklin Lakes, NJ) with $2 \% \mathrm{NaCl}$ and $20 \mu \mathrm{g} \mathrm{mL}^{-1}$ tetracycline at $25^{\circ} \mathrm{C}$. The transconjugant and recipient $E$. coli strains were cultured at $37^{\circ} \mathrm{C}$ in Luria Bertani medium (LB; BD) with and without 20 $\mu \mathrm{g} \mathrm{mL} \mathrm{mL}^{-1}$ tetracycline, respectively.

\section{Filter mating}

The donor strain was cultured to the mid-log phase in BHI with $2 \%(\mathrm{w} / \mathrm{v}) \mathrm{NaCl}$ and $20 \mu \mathrm{g} \mathrm{mL} \mathrm{m}^{-1}$ tetracycline at $25^{\circ} \mathrm{C}$. The recipient strain was cultured to the mid-log phase in $\mathrm{LB}$ at $37^{\circ} \mathrm{C}$. Filter mating was performed on $\mathrm{LB}$ agar plates at $25^{\circ} \mathrm{C}$ without antibiotic selection for $12 \mathrm{~h}$; and the transconjugants were selected as described previously (36). To see the transferability of pAQU1 from these transconjugants to an alternative recipient, two transconjugants (TJW2 and TJW13) were used as donors and W3110 Rif ${ }^{\mathrm{r}}$ was used as the recipient. Filter mating was performed on LB agar plates at $37^{\circ} \mathrm{C}$ for $6 \mathrm{~h}$; colonies that grew on the LB plates containing $20 \mu \mathrm{g}$ $\mathrm{mL}^{-1}$ tetracycline and $100 \mu \mathrm{g} \mathrm{mL}-1$ rifampicin at $37^{\circ} \mathrm{C}$ were selected and transfer of tet( $(\mathrm{M})$ was checked by PCR (38).

\section{Antimicrobial susceptibility test}

Minimal inhibitory concentrations (MICs) of E. coli were determined using the broth dilution method according to the NCCLS guidelines (35). For $P$. damselae subsp. damselae, we used the same method with modifications of the salt concentration to $2 \% \mathrm{NaCl}$, incubation temperature $\left(25^{\circ} \mathrm{C}\right)$ and culture period $(48 \mathrm{~h})$ appropriate for this microorganism (26).

\section{Pulsed field gel electrophoresis (PFGE) and hybridization}

The total DNA from the donor and recipient strains was fractionated using PFGE according to the S1 nuclease method developed for plasmids larger than $100 \mathrm{kbp} \mathrm{(3),} \mathrm{and} \mathrm{transferred} \mathrm{onto}$ a nylon membrane (GE Healthcare UK Ltd., Buckinghamshire, UK).
The plasmid DNA was detected using Southern blot hybridization (50). A 637 base pairs (bp) PCR product of tet(M) was labeled with digoxigenin using a PCR DIG probe synthesis kit (Roche Diagnostics, Mannheim, Germany), and used as the hybridization probe.

\section{Sequencing and annotation}

Total DNA containing both of the genomic and plasmid DNAs was extracted from a selected transconjugant using the QuickGene DNA tissue kit (Fujifilm, Tokyo, Japan) according to the manufacturer's protocol, and the purified DNA was sent to Takara Bio (Ohtsu, Japan) for sequencing. The whole sequence of the total DNA was determined by the pyro-sequencing method with a Genome Sequence FLX system using titanium chemistry (Roche Diagnostics). Approximately $5 \mu \mathrm{g}$ of the total DNA was used for the standard Roche 454 shotgun sequencing method, and a set of data having 628,489 sequences with an average length of 367 nucleotides was generated. The data were estimated to encompass 25 times the entire DNA sequence. From the data set, the genomic sequence of E. coli W3110 was subtracted leaving the plasmidderived sequences. The plasmid-derived sequences were then assembled de novo using the GS assembler (Newbler 2.0; Roche Diagnostics), and three sets of assembled contigs were generated. To fill the gaps between the contigs, PCR was performed using the total DNA template with LA Taq polymerase (Takara Bio), and with primers corresponding to the sequences close to the terminal ends of each contig. The nucleotide sequences of the PCR products were determined using the dideoxy chain termination method with a Big Dye terminator V 3.1 cycle sequencing kit (Life Technologies Corporation, Carlsbad, CA). Fidelity of the final assembly of the circular plasmid was confirmed using the scanning PCR method with 26 sets of primers designed with web-based software GenoFrag (60). The primers were optimized for long-range PCR to amplify the 26 segments covering the entire length of the plasmid. Preliminary identification of protein coding regions was performed using the MetaGeneAnnotator (37). The data were compared using BLAST for sequences in the NCBI non-redundant protein database for length, identity, and coverage; the final annotation was manually performed using the In Silico Molecular Cloning Genomics Edition (In Silico Biology, Yokohama, Japan).

\section{Phylogenetic analysis}

A BLAST search was performed using the amino acid sequence of pAQU1-encoded relaxase (Tral) as the query sequence. The TraI sequence was aligned using CLUSTAL W and compared with those of 24 other known TraI in the $\mathrm{MOB}_{\mathrm{H}}$ family (16) (Table S1). Twentyone highly conserved regions within the respective TraI sequences were joined using trimAL (8), generating 25 sets of approximately 450 amino acid sequences (Fig. S1). Finally, we used the neighborjoining (NJ) method with 1,000 bootstrap values, and similarities were compared using Molecular Evolutionary Genetics Analysis 5 (56).

\section{Nucleotide sequence accession number}

The entire sequence of pAQU1 is deposited in GenBank/DDBJ/ EMBL databases under accession no. AB571865.

\section{Results and Discussion}

\section{Transfer and detection of a 200-kbp conjugative plasmid carrying tet( $M$ )}

A previous study showed $\operatorname{tet}(\mathrm{M})$ was transferred from $P$. damselae subsp. damselae 04Ya311 to E. coli using conjugation with a transfer rate of $(6.62 \pm 1.61) \times 10^{-3}(36)$; therefore, filter mating experiments were performed to obtain transconjugants. To examine the location of the tet(M) gene in the $P$. damselae subsp. damselae 04Ya311 genome, we 


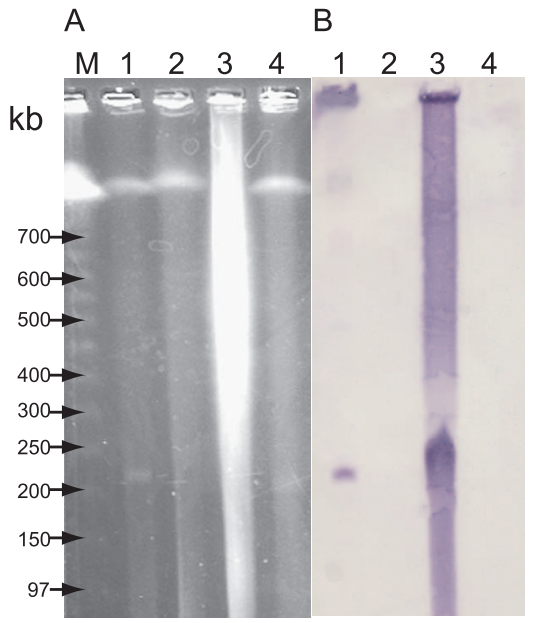

Fig. 1. Detection of plasmid pAQU1 in the donor and a representative transconjugant using PFGE (A) and Southern hybridization with the tet $(\mathrm{M})$ probe $(\mathrm{B})$. Lanes: M, DNA size standard (lambda ladder); 1, representative transconjugant $\mathrm{TJ} 311 \mathrm{~W} 2 ; 2, E$. coli $\mathrm{W} 3110 ; 3, P$. damselae subsp. damselae 04Ya311; and 4, negative control strain of $P$. damselae subsp. damselae JCM8967. About 20 ng of DNA was loaded in each lane.

performed PFGE and hybridization analysis using a tet(M) probe. The PFGE showed that an extra-chromosomal DNA of $\sim 200-\mathrm{kbp}$ was present in $P$. damselae subsp. damselae $04 \mathrm{Ya} 311$, and the position of the $\operatorname{tet}(\mathrm{M})$ hybridization signal corresponded to this extra-chromosomal DNA (Fig. 1B).

PFGE and subsequent hybridization showed that extrachromosomal DNA of $\sim 200-\mathrm{kbp}$ was present in the tetracycline-resistant transconjugant $E$. coli; but not in the recipient E. coli W3110 control (Fig. 1A, B). Twenty transconjugants were generated using independent filter mating experiments and were similarly examined, yielding the same data. Therefore, $\operatorname{tet}(\mathrm{M})$ appeared to be carried by a plasmid whose size was $\sim 200-\mathrm{kbp}$, unlike our previous report (36). In our previous study (36), we failed to detect this $200-\mathrm{kbp}$ plasmid because of the use of regular agarose gel electrophoresis, which cannot separate DNA fragments lager than approximately $20-\mathrm{kbp}$, instead of PFGE.

\section{General features of the $p A Q U 1$ sequence}

To characterize the $200-\mathrm{kbp}$ plasmid bearing tet $(\mathrm{M})$, the nucleotide sequence of the total DNA extracted from the transconjugant $E$. coli was determined using the pyrosequencing method. Because the entire sequence of $E$. coli W3110 was known, its sequence was subtracted from the whole sequence data. The three contigs after subtraction were shown to be continuous by using PCR, and further gap sequencing revealed the complete sequence of a circular plasmid, which was originally transferred from $P$. damselae subsp. damselae. The plasmid was named pAQU1; it contained 204,052 bp and 235 predicted coding sequences (CDSs). The gene organization and $\mathrm{G}+\mathrm{C}$ contents of the

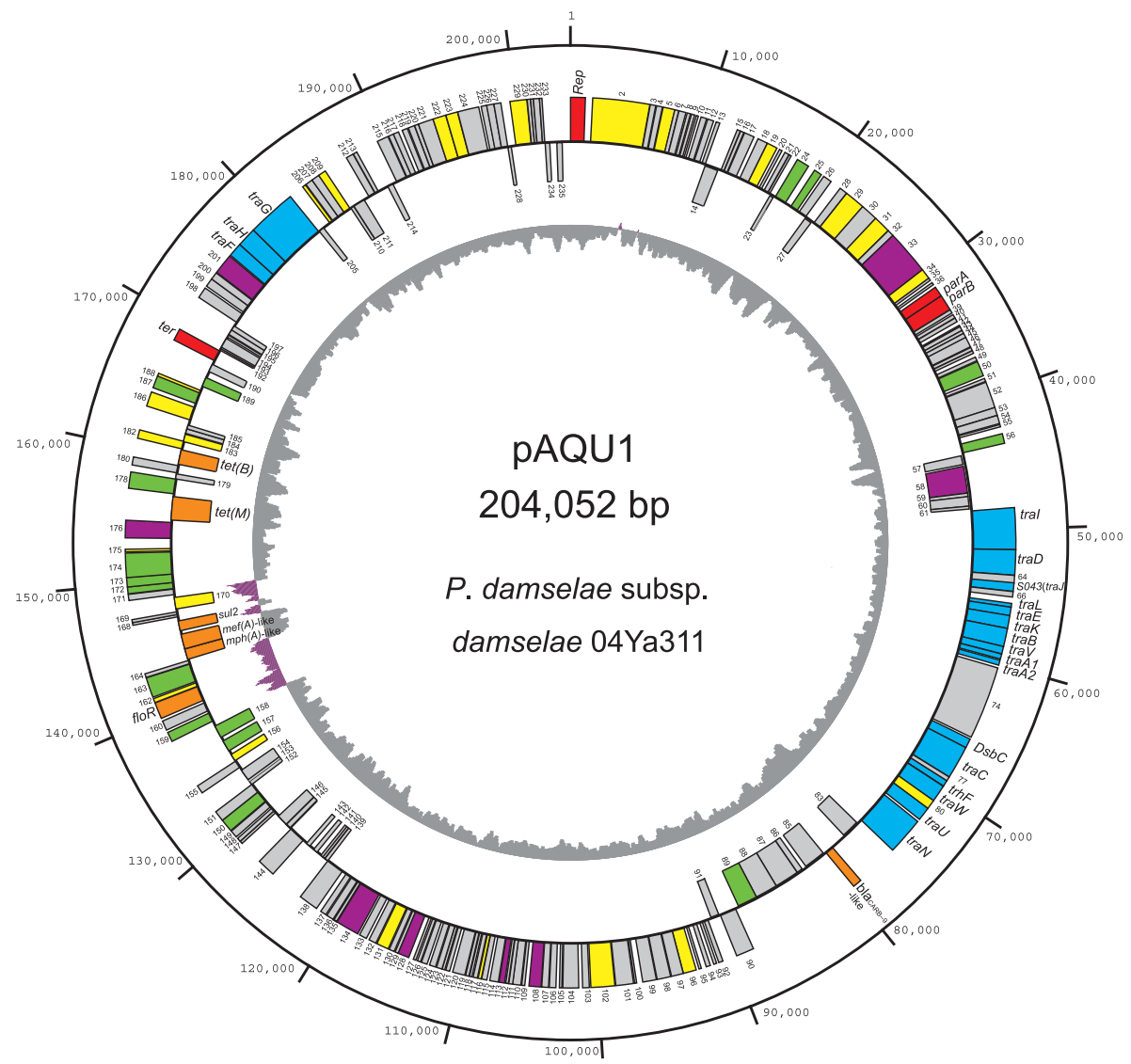

Fig. 2. Circular map of pAQU1. CDSs outside and inside of the circle are coded clockwise and counter-clockwise, respectively. Putative functions of the products of the CDSs are indicated in color: red, replication, partition and termination; purple, DNA processing; blue, conjugative transfer; green, transposition or integration; orange, antibiotic resistance; yellow, other functions; and gray, unknown functions. The third circle indicates GC content where purple shows upper GC value above the center line and gray shows lower GC value below the center line. 
Table 1. Classification of CDSs identified in pAQU1

\begin{tabular}{|c|c|c|c|c|c|}
\hline Putative function & $\begin{array}{l}\text { Similarity } \\
\text { observed }\end{array}$ & $\begin{array}{l}\text { CDS no. and } \\
\text { gene name }\end{array}$ & $\begin{array}{c}\text { Identity }(\%) \\
\text { (number of identical } \\
\text { amino acids/total } \\
\text { length) }\end{array}$ & $\begin{array}{l}\text { Query } \\
\text { coverage } \\
(\%)\end{array}$ & Protein similarity observed \\
\hline \multirow{3}{*}{$\begin{array}{l}\text { Replication, partition and } \\
\text { termination }\end{array}$} & \multirow{3}{*}{ Yes } & $037($ parA $)$ & $76(177 / 232)$ & 91 & Partition protein ParA \\
\hline & & $038($ parB $)$ & $57(233 / 407)$ & 100 & Transcriptional repressor protein KorB \\
\hline & & $191($ ter $)$ & $60(171 / 286)$ & 95 & DNA replication terminus site-binding protein \\
\hline \multirow{8}{*}{ DNA processing } & \multirow{8}{*}{ Yes } & 058 & $80(579 / 725)$ & 98 & DNA topoisomerase III \\
\hline & & 108 & $76(224 / 296)$ & 100 & DNA modification methylase \\
\hline & & 113 & $41(55 / 134)$ & 97 & Type IIA topoisomerase \\
\hline & & 128 & $79(158 / 201)$ & 72 & 5'-nucleotidase \\
\hline & & 134 & $60(353 / 592)$ & 98 & DNA primase \\
\hline & & 156 & $42(81 / 193)$ & 94 & DNA topoisomerase I \\
\hline & & 176 & $90(388 / 430)$ & 100 & RNA-directed DNA polymerase \\
\hline & & 229 & $74(306 / 412)$ & 99 & DNA methyltransferase \\
\hline \multirow[t]{18}{*}{ Conjugative transfer } & \multirow[t]{18}{*}{ Yes } & $062($ tral $)$ & $50(528 / 1058)$ & 99 & TraI \\
\hline & & $063($ traD $)$ & $81(504 / 621)$ & 99 & TraD \\
\hline & & $065(s 043)$ & $60(116 / 194)$ & 100 & Hypothetical protein \\
\hline & & $067(\operatorname{traL})$ & $75(157 / 209)$ & 100 & TraL \\
\hline & & $068(\operatorname{traE})$ & $68(141 / 208)$ & 99 & TraE \\
\hline & & $069(\operatorname{traK})$ & $61(192 / 314)$ & 99 & TraK \\
\hline & & $070(\operatorname{traB})$ & $57(251 / 443)$ & 98 & TraB \\
\hline & & $071($ traV $)$ & $63(120 / 189)$ & 98 & TraV \\
\hline & & $072(\operatorname{traA1})$ & $70(89 / 127)$ & 100 & TraA \\
\hline & & $073(\operatorname{traA2})$ & $67(82 / 123)$ & 100 & TraA \\
\hline & & $075(d s b C)$ & $60(122 / 203)$ & 85 & DsbC \\
\hline & & $076(\operatorname{traC})$ & $77(629 / 814)$ & 99 & TraC \\
\hline & & $078(\operatorname{trh} F)$ & $62(106 / 170)$ & 99 & TrhF \\
\hline & & $082(\operatorname{traN})$ & $66(613 / 929)$ & 99 & TraN \\
\hline & & $091(s 063)$ & $76(156 / 205)$ & 91 & Hypothetical protein \\
\hline & & $202($ traF $)$ & $55(174 / 318)$ & 88 & TraF \\
\hline & & $203($ traH $)$ & $70(337 / 479)$ & 99 & TraH \\
\hline & & $204(\operatorname{traG})$ & $71(860 / 1214)$ & 99 & TraG \\
\hline \multirow[t]{12}{*}{ Transposition } & \multirow[t]{12}{*}{ Yes } & 050 & $98(365 / 373)$ & 100 & ISVha1 (ISAs1 family) \\
\hline & & 056 & $95(229 / 240)$ & 100 & ISVba2 (IS5 family, IS903 group) \\
\hline & & 157 & $100(312 / 312)$ & 100 & ISVsa5 (IS4 family, IS10 group) \\
\hline & & 158 & $100(311 / 311)$ & 89 & ISShfr9 (Tn3 family) \\
\hline & & 159 & $99(238 / 239)$ & 100 & ISVsa3 (IS91 family) \\
\hline & & 163 & $100(497 / 497)$ & 100 & ISVsa3 (IS91 family) \\
\hline & & 172 & $98(161 / 165)$ & 97 & ISVsa5 (IS4 family, IS10 group) \\
\hline & & 173 & $99(236 / 237)$ & 100 & ISVsa5 (IS4 family, IS10 group) \\
\hline & & 174 & $99(586 / 587)$ & 97 & ISShfr9 (Tn3 family) \\
\hline & & 178 & $99(401 / 402)$ & 100 & ISVsa5 (IS4 family, IS10 group) \\
\hline & & 187 & $96(298 / 312)$ & 100 & ISVsa5 (IS4 family, IS10 group) \\
\hline & & 189 & $99(233 / 234)$ & 93 & ISVsa5 (IS4 family, IS10 group) \\
\hline \multirow[t]{4}{*}{ Integration } & \multirow[t]{4}{*}{ Yes } & 024 & $98(309 / 315)$ & 100 & Integrase core domain \\
\hline & & 025 & $94(186 / 197)$ & 100 & Integrase family protein \\
\hline & & 089 & $78(420 / 537)$ & 98 & Integrase family protein \\
\hline & & 150 & $60(191 / 321)$ & 99 & Integrase family protein \\
\hline \multirow[t]{7}{*}{ Antibiotic resistance } & \multirow[t]{7}{*}{ Yes } & 084 (bla $a_{\text {CARB-9-like })}$ & $100(223 / 223)$ & 100 & Beta lactamase class A (carbenicillinase) \\
\hline & & $161($ floR $)$ & $99(402 / 404)$ & 100 & Florfenicol/chloramphenicol resistance protein \\
\hline & & 165 (mph(A)-like) & $63(186 / 293)$ & 99 & Macrolide 2'-phosphotransferase $\operatorname{Mph}(\mathrm{A})$ \\
\hline & & 166 (mef(A)-like) & $51(208 / 407)$ & 99 & Macrolide efflux pump Mef(A) \\
\hline & & 167 (sul2) & $99(270 / 271)$ & 100 & Dihydropteroate synthase \\
\hline & & $177(\operatorname{tet}(\mathrm{M}))$ & $100(639 / 639)$ & 100 & Ribosomal protection protein TetM \\
\hline & & $181(\operatorname{tet}(\mathrm{B}))$ & $100(401 / 401)$ & 100 & Tetracycline efflux protein TetB \\
\hline
\end{tabular}




\begin{tabular}{|c|c|c|c|c|c|}
\hline \multirow[t]{22}{*}{ Others } & \multirow{22}{*}{ Yes } & 002 & $45(640 / 1419)$ & 99 & Rhs family protein \\
\hline & & 005 & $52(154 / 296)$ & 97 & Rhs family protein \\
\hline & & 019 & $98(235 / 240)$ & 92 & LabA-like protein \\
\hline & & 029 & $95(483 / 508)$ & 100 & Type I restriction enzyme M protein \\
\hline & & 031 & $53(225 / 428)$ & 99 & ATP-like protein \\
\hline & & 034 & $98(252 / 258)$ & 100 & Metal-dependent hydrolase \\
\hline & & 080 & $40(86 / 217)$ & 92 & $\begin{array}{l}\text { Cyclic diguanylate phosphodiesterase domain- } \\
\text { containing protein }\end{array}$ \\
\hline & & 096 & $78(249 / 320)$ & 99 & Aerobic cobaltochelatase subunit Cobs \\
\hline & & 102 & $66(400 / 605)$ & 100 & $\begin{array}{l}\text { Von Willebrand factor type A domain-containing } \\
\text { protein }\end{array}$ \\
\hline & & 116 & $58(43 / 74)$ & 97 & $\begin{array}{l}\text { Putative redox protein, regulator of disulfide } \\
\text { bond formation }\end{array}$ \\
\hline & & 131 & $47(131 / 278)$ & 92 & NgrC \\
\hline & & 162 & $100(101 / 101)$ & 100 & LysR family transcriptional regulator \\
\hline & & 170 & $100(237 / 237)$ & 100 & Mobilization protein $B$ \\
\hline & & 175 & $98(49 / 50)$ & 80 & Tn916, transcriptional regulator (ORF9) \\
\hline & & 182 & $100(208 / 208)$ & 100 & Tetracycline repressor protein TetR \\
\hline & & 183 & $100(207 / 207)$ & 100 & ArsR family transcriptional regulator \\
\hline & & 186 & $99(346 / 347)$ & 96 & Sodium/glutamate symport carrier protein \\
\hline & & 188 & $100(58 / 58)$ & 100 & Sodium/glutamate symporter (fragment) \\
\hline & & 206 & $68(48 / 71)$ & 86 & Ner-like DNA-binding protein \\
\hline & & 209 & $72(127 / 177)$ & 92 & Putative regulator protein \\
\hline & & 222 & $72(228 / 316)$ & 98 & Periplasmic serine protease \\
\hline & & 223 & $57(165 / 292)$ & 100 & DSBA-like thioredoxin domain protein \\
\hline Unknown & Yes or $\mathrm{No}^{\mathrm{a}}$ & $\begin{array}{l}003,004,006-018, \\
020-023,026-028,030, \\
032,035,036,039-049, \\
051-055,059,060,061, \\
064,066,074,077,083, \\
085-088,090,091-095, \\
097-101,103-107, \\
\text { 109-112, 114, 115, } \\
117-127,129,130,132, \\
133,135-149,151-155, \\
160,164,168,169,171, \\
179,180,184,185,190, \\
192-200,205,207,208, \\
210-221,224-228, \\
230-235\end{array}$ & $\mathrm{ND}^{\mathrm{b}}$ & ND & ND \\
\hline
\end{tabular}

a Yes, similarity was observed with hypothetical proteins; No, similarity was not observed with known or hypothetical proteins.

${ }^{\mathrm{b}} \mathrm{ND}$, not determined.

respective CDSs are summarized in Fig. 2. The CDSs were asymmetrically distributed: $182 \mathrm{CDSs}$ were oriented clockwise, whereas only $53 \mathrm{CDSs}$ were oriented counterclockwise. When a BLAST search was performed using the deduced amino acid sequences of the CDSs, related proteins of known functions were found for 78 out of the 235 CDSs. Based on their predicted function, these CDSs were classified into eight groups (Table 1). For the other 157 CDSs, similarity to other proteins with known functions was not found (Table 1). The average $\mathrm{G}+\mathrm{C}$ content of pAQU1 was $43.2 \%$; however, there was a region of notably higher $\mathrm{G}+\mathrm{C}$ contents at positions 140,000 to 150,000 (Fig. 2) that contained transposons and the floR gene (see "Drug resistance gene" section).

\section{Genes potentially involved in replication of pAQU1}

Principally, plasmid-encoded Rep proteins have $3^{\prime} \rightarrow 5^{\prime}$ helicase activity and initiate plasmid replication through binding to specific sequences in the replication origin and facilitating the interaction of host proteins with the origin (55). The deduced amino acid sequence of CDS 001 showed $33 \%$ (Table 1) identity to the putative replication protein (RepA) from Vibrio anguillarum and $24 \%$ identity to the
RepA protein of the well-characterized plasmid RSF1010 from $E$. coli (31). Thus, although pAQU1 appears to have a putative Rep protein, its sequence similarity with known RepA is low. Moreover, sequences similar to the primer sets conventionally used for PCR-based replicon typing (20) were not found to be effective for pAQU1. This suggests that pAQU1 contains a novel replicon capable of replicating in both $P$. damselae subsp. damselae and $E$. coli. A previous report showed that unknown types of plasmids are distributed among marine environmental bacteria $(11,54)$. So far, little is known about the diversity of marine plasmids, although they seem to play an important role in the dissemination of resistance genes in the marine environment (15).

Immediately downstream of CDS 001, there is an AT-rich region with five direct repeats and a set of inverted repeats (Fig. 3). The former is possibly an iteron, a region with ATrich direct repeats that serves as the binding site for the plasmid-encoded Rep initiator protein (55). Such a replication origin containing an iteron is common to a large group of plasmids including the IncQ group plasmids (RSF1010, R1162, and R300B), P1, F, pSC101, R6K, Rts1, pColIV$\mathrm{K} 30$, RK2, RP4, pCU1, pSa, and pPS10, as well as in the 


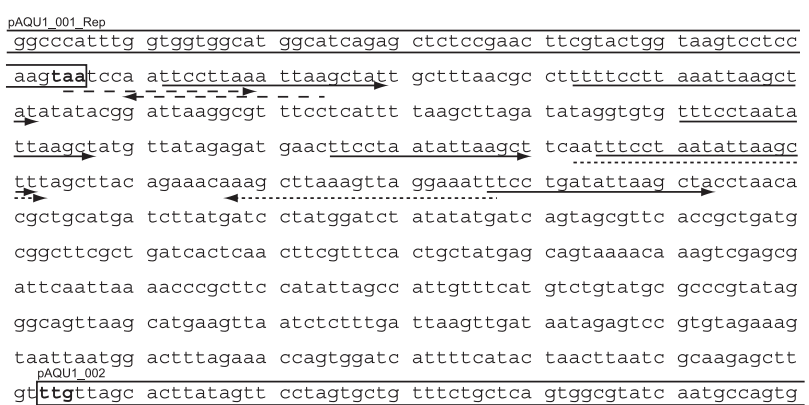

Fig. 3. DNA sequence of the potential replication origin region. CDSs are boxed. Arrows below the sequences indicate the 16 to 18 -bp AT-rich direct repeats. Inverted repeats of 15 and 21 bases are indicated by dashed lines.

lambda phage genome and in bacterial chromosomes (31, 55). Among these, an IncP group plasmid, RK2, has the iteron-type replication origin downstream of its Rep gene $(28,43)$. The iteron-like structure of the AT-rich region in pAQU1 and its position immediately downstream of the putative Rep protein gene suggests this region may correspond to the replication origin of pAQU1.

The plasmid partitioning system consists of two proteins encoded by independent genes often known as par $A$ and $\operatorname{par} B$ $($ kor $B)$, and a cis-acting centromere-like site, $\operatorname{par} S$ (14). The deduced amino acid sequences of CDSs 037 and 038 located $30-\mathrm{kb}$ downstream of CDS 001 were similar to ParA and ParB (KorB). The identities of the deduced amino acid sequences of CDSs 037 and 038 to those of ParA and ParB (KorB) proteins of the IncA/C plasmids were 75-76\% and 54-58\%, respectively, compared with those derived from P. damselae subsp. piscicida, (AB277723, AB277724), Yersinia ruckeri (CP000602), Yersinia pestis biovar Orientalis (CP000603), Salmonella enterica subsp. enterica serovar Newport (CP000604), E. coli (FJ621586, FJ621588, FJ705806), Salmonella enterica (AB277724), Aeromonas hydrophila (FJ705807), Xenorhabdus nematophila (FN667743), and A. salmonicida (CP000645).

The amino acid sequence of the product of CDS 191 had $60 \%$ identity to the DNA replication terminus site-binding protein (Tus) encoded by plasmids derived from Moritella sp. CDS 191 had 44-48\% identity at the amino acid level to Tus encoded by the group of IncA/C plasmids mentioned above (except for $A$. salmonicida). A similar degree of identity was also found between the product of pAQU1 CDS 191 and Tus encoded by an IncT plasmid derived from Proteus vulgaris (AP004237).

\section{Genes involved in conjugative transfer}

The deduced amino acid sequences of 18 CDSs $(062,063$, 067 through 073, 075, 076, 078, 079, 081, 082, and 202 through 204) showed $50-82 \%$ identity to those of the apparatus of the type IV secretion system (Table 1). In addition, there were two CDSs (065 and 091) whose deduced amino acid sequences were similar to those of the proteins encoded by genes $s 043$ and $s 063$ found in SXT. SXT/R391 is an integrative conjugative element (ICE) of less than 100 $\mathrm{kbp}$ that has been detected in clinical and environmental isolates (4). s043 and $s 063$ have been shown to be essential for conjugative transfer of SXT (58). pAQU1 has all 20 CDSs encoding the proteins that appear to be necessary for the type IV secretion system-dependent transfer, suggesting that conjugative transfer of this plasmid is mediated by this system. Furthermore, observation of the transfer of pAQU1 from transconjugants to the alternative recipient $E$. coli W3110Rif ${ }^{\mathrm{r}}$ (data was not shown) suggested that sufficient genes for this system were encoded on the plasmid. IncA/C plasmids also have both genes of the type IV secretion system proteins and genes similar to $s 043$ and $s 063$. Thus, IncA/C plasmids and SXT/R391 may have evolved from a common ancestral genetic element (58). Because pAQU1 shares the organization of the $20 \mathrm{CDSs}$ encoding proteins involved in conjugative transfer of the IncA/C plasmids and SXT/R391, pAQU1 may have evolved from the same ancestor.

Interestingly, pAQU1 has a pair of traA genes located together, traA1 and traA2, corresponding to CDSs 072 and 073, respectively. The TraA protein, a TrbC/VirB2 homologue, is a subunit of bacterial pili serving as a pathway for DNA transfer from a donor cell to a recipient cell (27). The deduced amino acid sequences of TraA 1 and TraA2 proteins encoded by pAQU1 are identical in length and $81 \%$ similar (101 residues/124). To incorporate TraA into mature pili, it is processed by removal of the 36-residue signal peptide and the 27-residue carboxyl terminal polypeptide (22). Amino acid sequences of the processed TraA 1 and TraA2 are highly conserved with only two amino acid differences (Fig. 4), suggesting they can both serve as functional subunits of pili. Phylogenetic analysis showed that pAQU1 TraA1 and TraA2 belong to an independent cluster separated from other known TraA proteins (data not shown). It may be possible traAl and $\operatorname{traA2}$ were generated by gene duplication within the plasmid. Another example of traA gene duplication is shown in the plasmid of Xenorhabdus nematophila ATCC 19061 (accession no. FN667743). Although the biological significance of traA gene duplication is unknown, it is possible that

\section{Core}

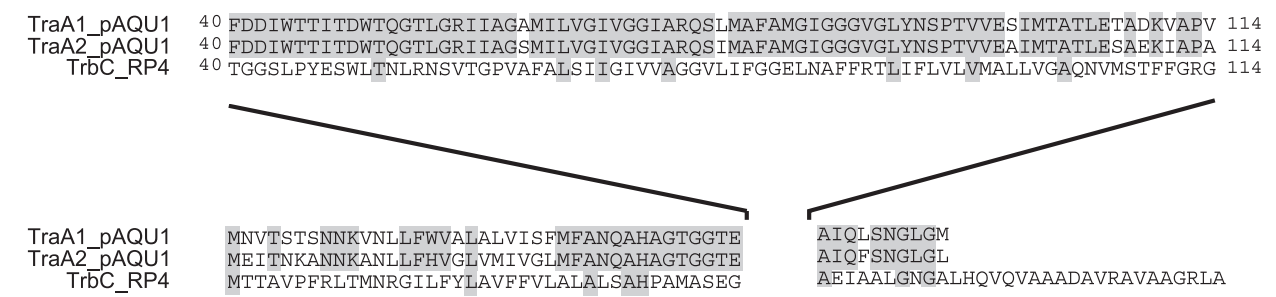

Fig. 4. Alignment of TraA homologues. Conserved amino acids are indicated by gray boxes. 
this may lead to an increased level of TraA expression and pili formation.

Plasmids encoding the proteins of the type IV secretion system have previously been found in pathogens for fish cultured in either seawater or freshwater, e.g. Aeromonas hydrophila, $P$. damselae subsp. piscicida, Y. ruckeri and $A$. salmonicida $(13,24,45,57)$. Our data show for the first time that bacteria carrying a conjugative plasmid could directly be isolated from seawater. Thus, conjugative transfer of the plasmid that carries multiple drug resistance genes may take place in the aquaculture environment and play an important role in the generation of multi-drug resistant pathogens.

\section{Drug resistance genes}

Deduced amino acid sequences of nine CDSs (084, 161, $165,166,167,177,179,180$ and 181) were found to be homologous to those of known drug resistance genes.

The nucleotide sequence of CDS 084 was identical to known but officially unnamed beta-lactamase genes (AB083415, AB453229) (Table 1) found in the plasmids of fish pathogen $P$. damselae subsp. piscicida strains isolated from cultured yellowtail (33). CDS 084 encodes a 224 aminoacid protein that has the serine-threonine-phenylalaninelysine (STFK) tetrad active site characteristic of serine beta-lactamases (21). Further, its 55\% similarity to a carbenicillin-hydrolyzing class A beta-lactamase (CARB-9) (44) and the presence of the arginine-serine-glycine (RSG) motif instead of the K-T/S-G motif of other class A betalactamases suggests that the product of CDS 084 is a

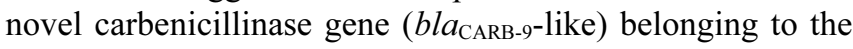
CARB family (44). As described above, a previous work detected this gene in some strains of $P$. damselae subsp. piscicida, suggesting that these carbenicillinase genes may be widely distributed among Photobacterium in the marine environment.

CDS 161 encodes a 405 amino-acid protein with $99 \%$ identity to FloR. FloR is a drug transporter of the major facilitator superfamily known as chloramphenicol and florfenicol resistance proteins. It is found in many Gramnegative bacteria including $E$. coli, $K$. pneumoniae, $S$. enterica, and $V$. cholerae. It is not uncommon for the transposase genes to be found upstream or downstream of the floR gene (51). DNA sequences upstream and downstream of CDS 161 are highly similar to the floR genes found in other plasmids and in the SXT element (51), appearing to contain putative transposase genes. CDS 161 is located in a region with a $\mathrm{GC} \%$ much higher than the average of the entire plasmid, suggesting that the CDS may have been exogenously introduced to pAQU1 by transposition.
Based on the deduced amino acid sequence, CDSs 165 and 166 showed $63 \%$ and $51 \%$ similarity to macrolide $2^{\prime}-$ phosphotransferase $\mathrm{Mph}(\mathrm{A})$ and macrolide efflux pump $\operatorname{Mef}(\mathrm{A})$, respectively $(9,47)$, where the latter belongs to the major facilitator superfamily of efflux pumps. There is a standardizing rule for the nomenclature of macrolide resistance genes that the new gene must have $<80 \%$ identity at the amino acid level with known macrolide resistance genes (47, 48); therefore, CDSs 165 and 166 are possibly new macrolide resistance genes, though their function needs to be confirmed to name them as new genes. CDS 167 encodes dihydropteroate synthase sul2 with $99 \%$ identity. This gene is found in many IncA/C plasmids $(24,57)$ and encodes dihydropteroate synthase with low affinity to sulfonamide, conferring resistance to the drug (53). The deduced amino acid sequences of CDSs 177 and 181 showed $100 \%$ similarity to the ribosomal protection protein and the efflux protein encoded by tet( $\mathrm{M})$ and tet(B), respectively (48). The BLAST search identified the deduced amino acid sequences of CDSs 179 and 180 as tetD and tetC (5), respectively, however, these were not characterized as tetracycline resistance determinants $(18,42)$, so we did not classify them as antibiotic resistance genes. Thus, many of the antibiotic resistance genes encoded on pAQU1 have quite high similarity to other corresponding genes, while some appear to be new genes.

Consistent with the annotation of the putative drug resistance genes, increases in MICs of the transconjugant were observed for ampicillin, carbenicillin, erythromycin, florfenicol and chloramphenicol, and plasmid-mediated transfer of drug resistance was confirmed (Table 2). Due to the inherent insusceptibility of the recipient strain of E. coli $\mathrm{W} 3110$, the transmission of resistance to sulfamethoxazole and sulfamonomethoxine could not be tested. Interestingly, all of the drug resistance genes found in pAQU1 had a corresponding drug that has been permitted for use in aquaculture in Japan (32). Oxytetracycline and flumequine had indeed been administered in the aquaculture area where $P$. damselae subsp. damselae strain 04Ya311 was obtained (38). Most of the drug resistance genes are localized in between 140,000 and 160,000 positions and are flanked by transposase genes, apparently making an island region. The sequential transposition events and drug selection in the environment possibly played a role in constructing a multidrug resistance island in the plasmid. Thus, plasmids possessed by bacteria in the aquaculture environment serve as an important reservoir for the various antibiotic resistance genes. The transfer of resistance genes among plasmids and/ or chromosomes of different bacteria may also occur in the environment. Impact of this ability to transfer among bacteria

Table 2. Susceptibility of the donor strain of $P$. damselae subsp. damselae $04 \mathrm{Ya} 311$, the transconjugant TJ311W2, and E. coli W3110 to antimicrobial agents

\begin{tabular}{llrrrrrrrr}
\hline \multirow{2}{*}{ Strain name } & \multirow{2}{*}{ Species } & \multicolumn{7}{c}{ Minimal inhibitory concentration $(\mu \mathrm{g} / \mathrm{ml})^{\mathrm{a}}$} \\
\cline { 3 - 10 } & & AMP & CAR & TET & ERY & CHL & FLO & SMXZ & SMX \\
\hline 04Ya311 & P. damselae subsp. damselae & $>128$ & $>128$ & 8 & 128 & 8 & 16 & $>512$ & $>512$ \\
TJ311W2 & E. coli & 64 & $>128$ & 16 & 128 & 8 & 16 & $>512$ & $>512$ \\
\hline W3110 & E. coli & 0.125 & 1 & $<0.125$ & 32 & 0.5 & 1 & $>512$ & $>512$ \\
\hline
\end{tabular}

a AMP, ampicillin; CAR, carbenicillin; TET, tetracycline; ERY, erythromycin; CHL, chloramphenicol; FLO, florfenicol; SMXZ, sulfamethoxazole; SMX, sulfamonomethoxine 


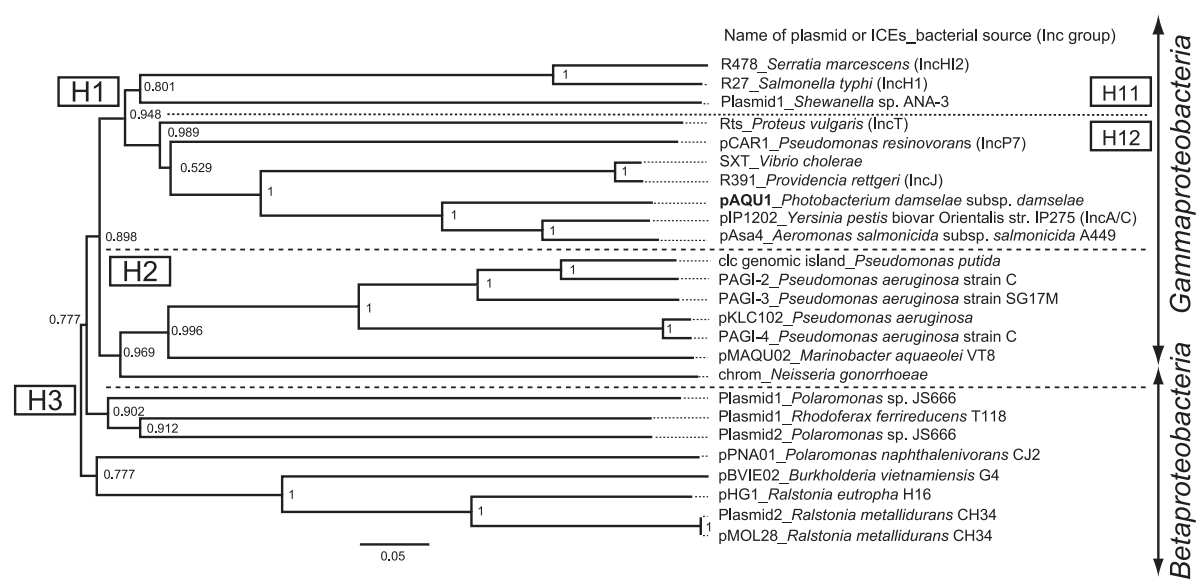

Fig. 5. Phylogenetic tree of relaxases (TraI) from plasmids and SXT/R391 that belong to the $\mathrm{MOB}_{\mathrm{H}}$ family.

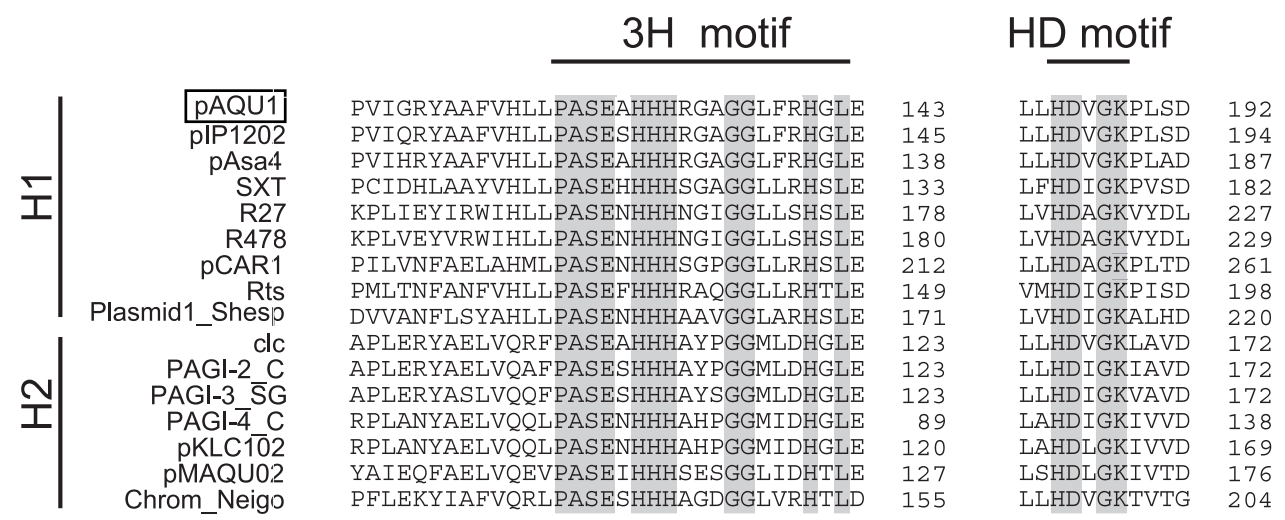

Fig. 6. Conserved sequence motifs in relaxases (TraI) grouped in the $\mathrm{MOB}_{\mathrm{H}}$ family. Both of the $3 \mathrm{H}$ and HD hydrolase motifs indicated by gray boxes are conserved in the relaxase encoded by pAQU1.

needs to be investigated in relation to the emergence of resistance in fish pathogens (23) or aquatic environmental bacteria $(15,38)$.

\section{Phylogenetic position of pAQU1}

To characterize and classify the plasmids derived from human clinical isolates, replicon typing using DNA hybridization or PCR can be used (10). However, replicon typing tends to be difficult to apply to plasmids isolated from marine bacteria because their classification does not fit the plasmids derived from human clinical isolates $(11,54)$. Recently, comparison of the primary structures of traI gene products (relaxase) was successfully used for phylogenetic analysis and classification of the conjugative transfer system in six MOB families. Therefore, comparison of relaxases may be useful for plasmid classification (16). Relaxase is an essential enzyme for the type IV secretion system and cleaves at a specific site called oriT when it is transferred to another bacterial cell by conjugation. Because the replicon type for pAQU1 could not be determined as mentioned above, phylogenetic analysis of pAQU1 was performed based on the deduced amino acid sequence of relaxase it encodes.

The data indicate that pAQU1 is a member of the $\mathrm{MOB}_{\mathrm{H}}$ family and grouped in $\mathrm{MOB}_{\mathrm{H} 12}$ together with IncJ, IncT, IncP7, and IncA/C (Fig. 5). The relaxase encoded by pAQU1 has both $3 \mathrm{H}$ and $\mathrm{HD}$ motifs [(H/Q)-X $\mathrm{X}_{2}$ PASE-X-HHH-X ${ }_{3}^{-}$
GG-X $-\mathrm{H}-\mathrm{X}-\mathrm{L}$ and (L/V)-X-HD-(A/V/L/I)-GK, respectively] known to be shared by relaxases of the $\mathrm{MOB}_{\mathrm{H} 1}$ and $\mathrm{MOB}_{\mathrm{H} 2}$ clades (Fig. 6). Among the $\mathrm{MOB}_{\mathrm{H} 12}$ plasmids, pAQU1 is most closely related to IncA/C plasmid and SXT/R391. In addition to the organizations of the $20 \mathrm{CDSs}$ encoding the type IV secretion system proteins, the primary structure of the relaxase also demonstrated a close evolutionary relationship of pAQU1 with the Inc A/C plasmid and SXT/R391; however, the DNA sequence of the traI gene of pAQU1 is clearly different from those of the IncA/C plasmids and SXT/ $\mathrm{R} 391$. Recently, evidence suggested that the IncA/C plasmids $(7,25,30,57)$ and SXT/R391 (4) found in various ecological niches may be responsible for the generation of multi-drug resistant bacteria. Similarly, pAQU1, also classified in $\mathrm{MOB}_{\mathrm{H} 12}$, may play a similar role in the aquaculture environment, as well as in clinical settings. To examine this possibility, further investigations concerning the distribution of the 'pAQU1-type' plasmid will be necessary.

\section{Acknowledgements}

This work was supported by Grants-in-Aid for Scientific Research (20780141, 22592032, 23390102, 23593043 and 23659220) from the Japan Promotion Society (JSPS) and a Research Promotion Award from Dokkyo Medical University School of Medicine. We are grateful to Dr. Satoru Suzuki, Center for Marine Environments, Ehime University, Japan for providing bacterial isolates. We thank 
Dr. Takuro Nunoura, Japan Agency for Marine-Earth Science \& Technology for critical advises. We thank Yuki Shinozaki, Satomi Kato, Kayoko Kobayashi and Takashi Namatame for technical assistance.

\section{References}

1. Alcaide, E. 2003. Numerical taxonomy of Vibrionaceae isolated from cultured amberjack (Seriola dumerili) and surrounding water. Curr. Microbiol. 46:184-189.

2. Barber, G.R., and J.S. Swygert. 2000. Necrotizing fasciitis due to Photobacterium damsela in a man lashed by a stingray. N. Engl. J. Med. 342:824.

3. Barton, B.M., G.P. Harding, and A.J. Zuccarelli. 1995. A general method for detecting and sizing large plasmids. Anal. Biochem. 226:235-240.

4. Burrus, V., J. Marrero, and M.K. Waldor. 2006. The current ICE age: biology and evolution of SXT-related integrating conjugative elements. Plasmid 55:173-183.

5. Braus, G., M. Argast, and C.F. Beck. 1984. Identification of additional genes on transposon $\mathrm{Tn} 10$ : tetC and tetD. J. Bacteriol 160:504-509.

6. Cabello, F.C. 2006. Heavy use of prophylactic antibiotics in aquaculture: a growing problem for human and animal health and for the environment. Environ. Microbiol. 8:1137-1144.

7. Call, D.R., R.S. Singer, D. Meng, et al. 2010. bla $a_{\mathrm{CMY}-2 \text {-positive IncA/ }}$ C plasmids from Escherichia coli and Salmonella enterica are a distinct component of a larger lineage of plasmids. Antimicrob. Agents Chemother. 54:590-596.

8. Capella-Gutiérrez, S., J.M. Silla-Martínez, and T. Gabaldón. 2009. trimAl: a tool for automated alignment trimming in large-scale phylogenetic analyses. Bioinformatics 25:1972-1973.

9. Clancy, J., J. Petitpas, F. Dib-Hajj, W. Yuan, M. Cronan, A.V. Kamath, J. Bergeron, and J.A. Retsema. 1996. Molecular cloning and functional analysis of a novel macrolide-resistance determinant, mefA, from Streptococcus pyogenes. Mol. Microbiol. 22:867-879.

10. Couturier, M., F. Bex, P.L. Bergquist, and W.K. Maas. 1988. Identification and classification of bacterial plasmids. Microbiol. Rev. 52:375-395.

11. Dahlberg, C., C. Linberg, V.L. Torsvik, and M. Hermansson. 1997. Conjugative plasmids isolated from bacteria in marine environments show various degrees of homology to each other and are not closely related to well-characterized plasmids. Appl. Environ. Microbiol 63:4692-4697.

12. Fraser, S.L., B.K. Purcell, B. Delgado, Jr., A.E. Baker, and A.C. Whelen. 1997. Rapidly fatal infection due to Photobacterium (Vibrio) damsela. Clin. Infect. Dis. 25:935-936.

13. Fricke, W.F., T.J. Welch, P.F. McDermott, M.K. Mammel, J.E. LeClerc, D.G. White, T.A. Cebula, and J. Ravel. 2009. Comparative genomics of the IncA/C multidrug resistance plasmid family. J. Bacteriol. 191:4750-4757.

14. Funnell, B.E., and R.A. Slavcev. 2004. Partition systems of bacterial plasmid, p. 81-103. In B.E. Funnell and G.J. Phillips (ed.), Plasmid Biology. ASM Press, Washington, DC.

15. Furushita, M., T. Shiba, T. Maeda, et al. 2003. Similarity of tetracycline resistance genes isolated from fish farm bacteria to those from clinical isolates. Appl. Environ. Microbiol. 69:5336-5342.

16. Garcillán-Barcia, M.P., M.V. Francia, and F. de la Cruz. 2009. The diversity of conjugative relaxases and its application in plasmid classification. FEMS Microbiol. Rev. 33:657-687.

17. Goodell, K.H., M.R. Jordan, R. Graham, C. Cassidy, and S.A. Nasraway. 2004. Rapidly advancing necrotizing fasciitis caused by Photobacterium (Vibrio) damsela: a hyperaggressive variant. Crit Care Med. 32:278-281.

18. Griffith, K.L., S.M. Becker, and R.E. Wolf, Jr. 2005. Characterization of $T e t D$ as a transcriptional activator of a subset of genes of the Escherichia coli SoxS/MarA/Rob regulon. Mol. Microbiol. 56:11031117.

19. Hayashi, K., N. Morooka, Y. Yamamoto, et al. 2006. Highly accurate genome sequences of Escherichia coli K-12 strains MG1655 and W3110. Mol. Syst. Biol. 2:2006 0007.

20. Johnson, T.J., and L.K. Nolan. 2009. Plasmid replicon typing. Methods Mol. Biol. 551:27-35.
21. Joris, B., P. Ledent, O. Dideberg, E. Fonze, J. Lamotte-Brasseur, J.A Kelly, J.M. Ghuysen, and J.M. Frere. 1991. Comparison of the sequences of class A $\beta$-lactamases and of the secondary structure elements of penicillin-recognizing proteins. Antimicrob. Agents Chemother. 35:2294-2301.

22. Kalkum, M., R. Eisenbrandt, R. Lurz, and E. Lanka. 2002. Tying rings for sex. Trends Microbiol. 10:382-387.

23. Kim, S.R., L. Nonaka, and S. Suzuki. 2004. Occurrence of tetracycline resistance genes $\operatorname{tet}(\mathrm{M})$ and $\operatorname{tet}(\mathrm{S})$ in bacteria from marine aquaculture sites. FEMS Microbiol. Lett. 237:147-156.

24. Kim, M.J., I. Hirono, K. Kurokawa, T. Maki, J. Hawke, H. Kondo, M.D. Santos, and T. Aoki. 2008. Complete DNA sequence and analysis of the transferable multiple-drug resistance plasmids (R Plasmids) from Photobacterium damselae subsp. piscicida isolates collected in Japan and the United States. Antimicrob. Agents Chemother. 52:606611.

25. Kumarasamy, K.K., M.A. Toleman, T.R. Walsh, et al. 2010. Emergence of a new antibiotic resistance mechanism in India, Pakistan, and the UK: a molecular, biological, and epidemiological study. Lancet Infect. Dis. 10:597-602.

26. Kawanishi, M., A. Kojima, K. Ishihara, et al. 2004. Quality control ranges of minimum inhibitory concentrations for Lactococcus garvieae and Photobacterium damselae subsp. piscicida. Fish Pathol. 39:111-114.

27. Lawley, T.D., W.A. Klimke, M.J. Gubbins, and L.S. Frost. 2003 $\mathrm{F}$ factor conjugation is a true type IV secretion system. FEMS Microbiol. Lett. 224:1-15.

28. Llanes, C., P. Gabant, M. Couturier, and Y. Michel-Briand. 1994. Cloning and characterization of the Inc A/C plasmid RA1 replicon. J. Bacteriol. 176:3403-3407.

29. Love, M., D. Teebken-Fisher, J.E. Hose, J.J. Farmer, 3rd, F.W. Hickman, and G.R. Fanning. 1981. Vibrio damsela, a marine bacterium, causes skin ulcers on the damselfish Chromis punctipinnis. Science 214:1139-1140.

30. McIntosh, D., M. Cunningham, B. Ji, et al. 2008. Transferable, multiple antibiotic and mercury resistance in Atlantic Canadian isolates of Aeromonas salmonicida subsp. salmonicida is associated with carriage of an IncA/C plasmid similar to the Salmonella enterica plasmid pSN254. J. Antimicrob. Chemother. 61:1221-1228.

31. Meyer, R. 2009. Replication and conjugative mobilization of broad host-range IncQ plasmids. Plasmid 62:57-70.

32. Ministry of Agriculture, Forestry and Fisheries. 2011. Protocols for the use of antimicrobial agents in aquaculture (version 24) (in Japanese).

33. Morii, H., M.S. Bharadwaj, and N. Eto. 2004. Cloning and nucleotide sequence analysis of the ampicililin resistance gene on a conjugative $\mathrm{R}$ plasmid from the fish pathogen Photobacterium damselae subsp. piscicida. J. Aquat. Anim. Health 16:197-207.

34. Nakamura, Y., M. Uchihira, M. Ichimiya, K. Morita, and M. Muto. 2008. Necrotizing fasciitis of the leg due to Photobacterium damsela. J. Dermatol. 35:44-45.

35. National Committee for Clinical Laboratory Standards (NCCLS) 2003. Methods for Dilution Antimicrobial Susceptibility Tests for Bacteria That Grow Aerobically. Approved standard M7-A6. NCCLS, Wayne, PA.

36. Neela, F.A., L. Nonaka, M.H. Rahman, and S. Suzuki. 2009. Transfer of the chromosomally encoded tetracycline resistance gene tet $(\mathrm{M})$ from marine bacteria to Escherichia coli and Enterococcus faecalis. World J. Microbiol. Biotechnol. 25:1095-1101.

37. Noguchi, H., T. Taniguchi, and T. Itoh. 2008. MetaGeneAnnotator: detecting species-specific patterns of ribosomal binding site for precise gene prediction in anonymous prokaryotic and phage genomes. DNA Res. 15:387-396.

38. Nonaka, L., K. Ikeno, and S. Suzuki. 2007. Distribution of tetracycline resistance gene, tet $(\mathrm{M})$, in Gram-positive and Gram-negative bacteria isolated from sediment and seawater at a coastal aquaculture site in Japan. Microbes Environ. 22:355-364.

39. Osorio, C.R., A.E. Toranzo, J.L. Romalde, and J.L. Barja. 2000. Multiplex PCR assay for ureC and 16S rRNA genes clearly discriminates between both subspecies of Photobacterium damselae. Dis Aquat. Organ. 40:177-183.

40. Pedersen, K., I. Dalsgaard, and J.L. Larsen. 1997. Vibrio damsela associated with diseased fish in Denmark. Appl. Environ. Microbiol. $63: 3711-3715$ 
41. Pedersen, K., H.F. Skall, A.M. Lassen-Nielsen, L. Bjerrum, and N.J. Olesen. 2009. Photobacterium damselae subsp. damselae, an emerging pathogen in Danish rainbow trout, Oncorhynchus mykiss (Walbaum), mariculture. J. Fish. Dis. 32:465-472.

42. Pepe, C.M., C. Suzuki, C. Laurie, and R.W. Simons. 1997. Regulation of the "tetCD" genes of transposon Tn10. J. Mol. Biol. 270:14 25.

43. Perri, S., D.R. Helinski, and A. Toukdarian. 1991. Interactions of plasmid-encoded replication initiation proteins with the origin of DNA replication in the broad host range plasmid RK2. J. Biol. Chem. 266:12536-12543.

44. Petroni, A., R.G. Melano, H.A. Saka, et al. 2004. CARB-9, a carbenicillinase encoded in the VCR region of Vibrio cholerae non-O1, nonO139 belongs to a family of cassette-encoded $\beta$-lactamases. Antimicrob. Agents Chemother. 48:4042-4046.

45. Reith, M.E., R.K. Singh, B. Curtis, et al. 2008. The genome of Aeromonas salmonicida subsp. salmonicida A449: insights into the evolution of a fish pathogen. BMC Genomics 9:427.

46. Richards, G.P., M.A. Watson, E.J. Crane, 3rd, I.G. Burt, and D. Bushek. 2008. Shewanella and Photobacterium spp. in oysters and seawater from the Delaware Bay. Appl. Environ. Microbiol. 74:33233327.

47. Roberts, M.C., J. Sutcliffe, P. Courvalin, L.B. Jensen, J. Rood, and H. Seppala. 1999. Nomenclature for macrolide and macrolidelincosamide-streptogramin B resistance determinants. Antimicrob. Agents Chemother. 43:2823-2830.

48. Roberts, M.C. 2005. Update on acquired tetracycline resistance genes. FEMS Microbiol Lett 245:195-203.

49. Roberts, M.C. 2008. Update on macroride-lincosamid-streptogramin, ketlide, and oxazolidinone resistance genes. FEMS microbial. Lett. 282:147-159.

50. Sambrook, J., and D.W. Russell. 2001. Molecular Cloning: A Laboratory Manual, 3rd ed. Cold Spring Harbor Laboratory Press, Cold Spring Harbor, N.Y.
51. Schwarz, S., C. Kehrenberg, B. Doublet, and A. Cloeckaert. 2004 Molecular basis of bacterial resistance to chloramphenicol and florfenicol. FEMS Microbiol. Rev. 28:519-542.

52. Shin, J.H., M.G. Shin, S.P. Suh, D.W. Ryang, J.S. Rew, and F.S. Nolte. 1996. Primary Vibrio damsela septicemia. Clin. Infect. Dis. 22:856-857.

53. Skold, O. 2000. Sulfonamide resistance: mechanisms and trends. Drug Resist. Updat. 3:155-160.

54. Sobecky, P.A., T.J. Mincer, M.C. Chang, and D.R. Helinski. 1997. Plasmids isolated from marine sediment microbial communities contain replication and incompatibility regions unrelated to those of known plasmid groups. Appl. Environ. Microbiol. 63:888-895.

55. Solar, G.D., R. Giraldo, M.J. Ruiz-Echevarría, M. Espinosa, and R. Díaz-Orejas. 1998. Replication and control of circular bacterial plasmids. Microbiol. Mol. Biol. Rev. 62:434-464.

56. Tamura, K., D. Peterson, N. Peterson, G. Stecher, M. Nei, and S. Kumar. 2011. MEGA5: Molecular evolutionary genetics analysis using maximum likelihood, evolutionary distance, and maximum parsimony methods. Mol. Biol. Evol. [Epub ahead of print]

57. Welch, T.J., W.F. Fricke, P.F. McDermott, et al. 2007. Multiple antimicrobial resistance in plague: an emerging public health risk. PLoS One 2:e309.

58. Wozniak, R.A., D.E. Fouts, M. Spagnoletti, M.M. Colombo, D Ceccarelli, G. Garriss, C. Dery, V. Burrus, and M.K. Waldor. 2009. Comparative ICE genomics: insights into the evolution of the SXT/ R391 family of ICEs. PLoS Genet. 5:e1000786.

59. Yamane, K., J. Asato, N. Kawade, H. Takahashi, B. Kimura, and Y. Arakawa. 2004. Two cases of fatal necrotizing fasciitis caused by Photobacterium damsela in Japan. J. Clin. Microbiol. 42:1370-1372.

60. Zakour, N.B., M. Gautier, R. Andonov, D. Lavenier, M.F. Cochet, P. Veber, A. Sorokin, and Y. Le Loir. 2004. GenoFrag: software to design primers optimized for whole genome scanning by long-range PCR amplification. Nucleic Acids Res. 32:17-24. 